\title{
Emerging data on androgen receptor splice variants in prostate cancer
}

\author{
Subing Cao ${ }^{1,2}$, Yang Zhan ${ }^{1,2}$ and Yan Dong1,2 \\ ${ }^{1}$ College of Life Sciences, Jilin University, Changchun, Jilin, China \\ 2Department of Structural and Cellular Biology, Tulane University School of Medicine, Tulane Cancer Center, \\ New Orleans, Louisiana, USA
}

Correspondence should be addressed to $Y$ Dong

Email

ydong@tulane.edu

\begin{abstract}
Androgen receptor splice variants are alternatively spliced variants of androgen receptor, which are C-terminally truncated and lack the canonical ligand-binding domain. Accumulating evidence has indicated a significant role of androgen receptor splice variants in mediating resistance of castration-resistant prostate cancer to current therapies and in predicting therapeutic responses. As such, there is an urgent need to target androgen receptor splicing variants for more effective treatment of castrationresistant prostate cancer. Identification of precise and critical targeting points to deactivate androgen receptor splicing variants relies on a deep understanding of how they are generated and the mechanisms of their action. In this review, we will focus on the emerging data on their generation, clinical significance and mechanisms of action as well as the therapeutic influence of these findings.
\end{abstract}
Key Words
- androgen receptor
- splice variant
- prostate cancer
- dimerization
- cofactors

Endocrine-Related Cancer (2016) 23, T199-T210

\section{Introduction}

The androgen receptor (AR) signaling pathway remains active in castration-resistant prostate cancer (CRPC) (reviewed in Knudsen \& Scher 2009, Egan et al. 2014, Kahn et al. 2014). Mechanisms leading to AR reactivation include intra-tumoral androgen production, alterations in AR expression level and structure, AR gene mutations and transcriptional activation of AR by non-androgen ligands and AR cofactors as well as by the crosstalk with growth factor signaling pathways (reviewed in Knudsen \& Scher 2009, Egan et al. 2014, Kahn et al. 2014). Abiraterone and enzalutamide were developed to target intra-tumoral androgen production and AR overexpression, respectively, but resistance inevitably occurs during treatment (Attard et al. 2008, Tran et al. 2009, de Bono et al. 2011, Fizazi et al. 2012, Scher et al. 2012, Ryan et al. 2013). Recent studies have implicated constitutively active androgen receptor splice variants (AR-Vs) as a potential driver of resistance to these treatments (Mostaghel et al. 2011, Efstathiou et al. 2012,
Li et al. 2013, Nadiminty et al. 2013, Antonarakis et al. 2014, Cao et al. 2014, Yamamoto et al. 2015).

As a steroid receptor, AR activity is not only regulated by ligand binding but also affected by protein-protein interactions, including homodimerization and interactions with cofactors (reviewed in Gelmann 2002, Chan \& Dehm 2014). The recruitment and formation of multiple protein complexes are required to activate or repress downstream gene expression. The same rules can be applied to AR-Vs. Several studies indicated that AR-Vs may activate different gene profiles in a cell-context-specific manner (reviewed in Lu et al. 2015). However, the factors that determine the specificity of AR-V-regulated gene sets are currently unknown. One appealing mechanism is that selective gene targeting is achieved by different protein complexes formed between AR-Vs and their partners and/or cofactors, which may induce the formation of novel interfaces to allow the installment of the general transcriptional machinery.

This paper is part of a thematic review section on hormone-dependent cancers. The Guest Editor for this section was Wayne Tiley. 
In this review, we summarize the recent discoveries about the mechanisms of AR-V generation, their clinical values, and the modulation of their transcriptional activity by their dimerization partners and cofactors in CRPC.

\section{AR-V structure}

To date, over 20 AR variants have been identified in human prostate cancer cell models and clinical specimens (Fig. 1). Some of these variants are constitutively active, such as AR-V7 and ARv567es (aka AR-V12), whereas some others are conditionally active, depending on the cellular context, such as AR-V1 and AR-V9 (Hu et al. 2011). Except AR45, which is truncated in the N-terminal domain, all the other variants contain an intact $\mathrm{N}$-terminal domain but lack portions of the ligand-binding domain (LBD). As the N-terminal domain harbors the two trans-activating regions

A

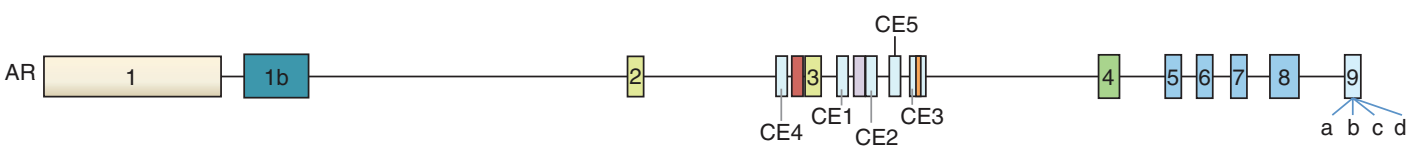

B

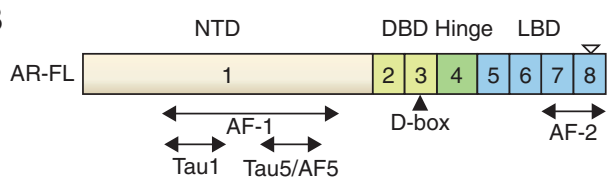

C

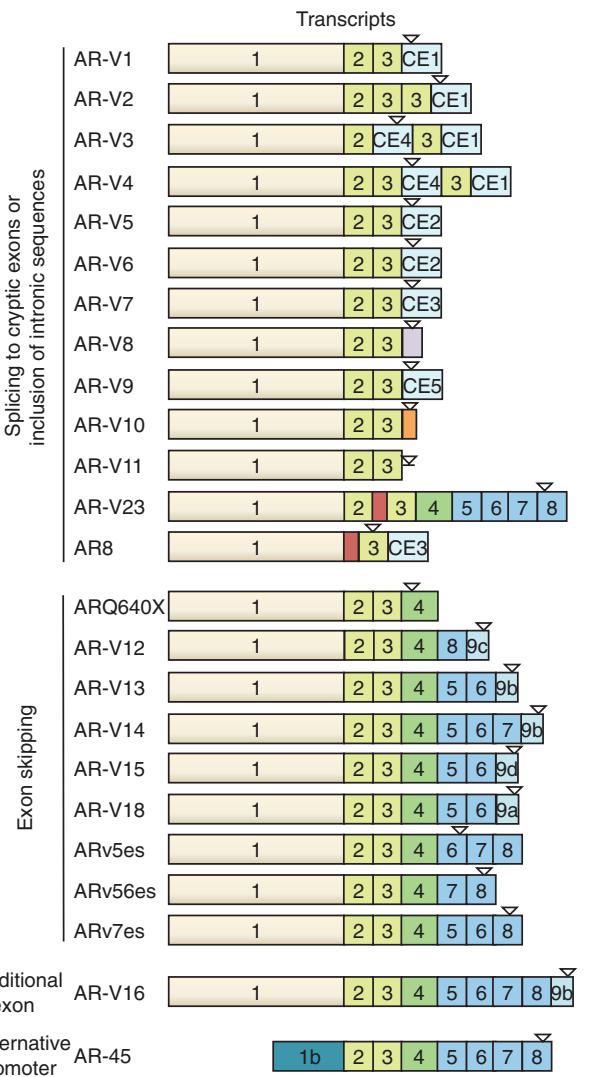

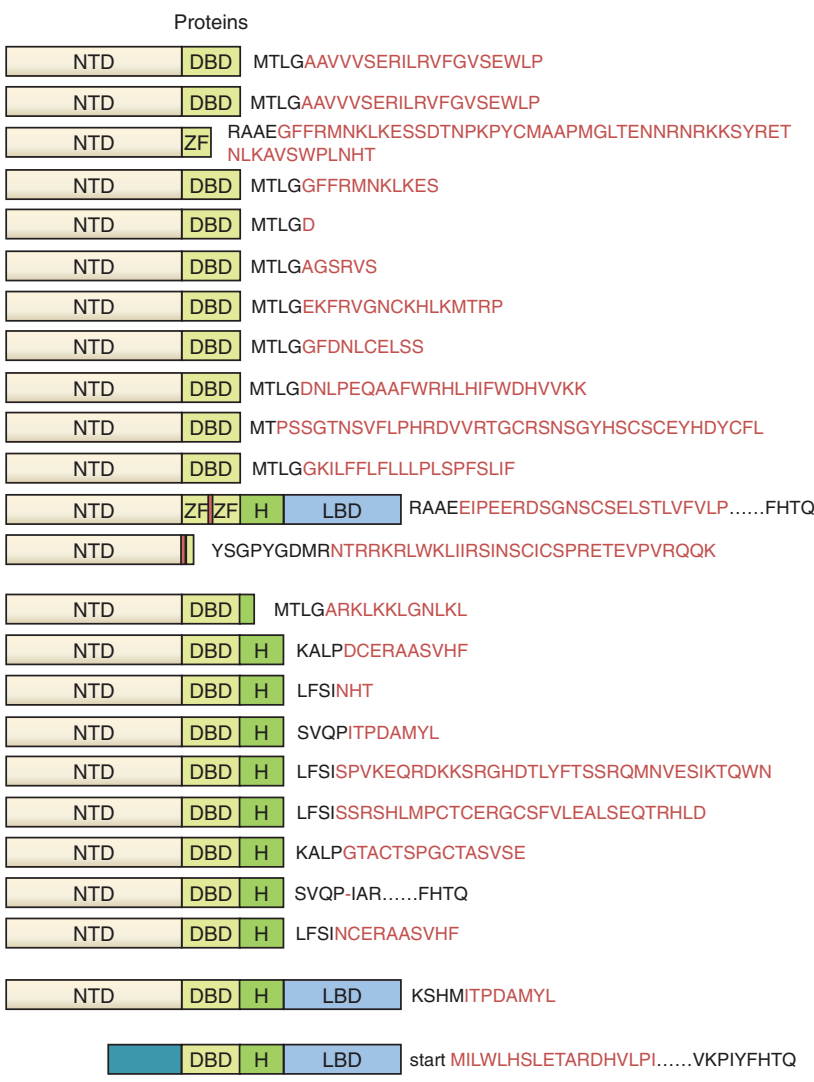

Figure 1

Schematic representation of the structure of AR-FL and AR-V transcripts and proteins. (A) AR gene structure with canonical exons and the cryptic exons (CE). (B) AR-FL mRNA structure showing exons encoding the N-terminal domain (NTD; exon 1), DNA-binding domain (DBD; exons 2 and 3), hinge region (part of exons 3 and 4) and ligand-binding domain (LBD; exons 5-8). AF-1, Tau1, Tau5/AF-5 and AF-2 are activation function domains. Filled triangle depicts the D-box, which mediates AR-V/AR-V, AR-V/AR-FL and AR-FL/AR-FL dimerization. (C) mRNA and protein structures of AR-Vs. AR-V-specific peptide sequences are indicated in red, and the ' - ' in ARv56es indicates a unique junction. Inverted open triangle depicts translation stop. Drawings are not to scale. Exon 9 harbors four cryptic $3^{\prime}$ splicing sites, and the corresponding cryptic exons are indicated as 9a, 9b, 9c and 9d. 
(Tau1 and Tau5/AF5), AR45 loses its trans-activating ability and acts as a dominant-negative variant to inhibit the function of the full-length AR (AR-FL) by forming a heterodimer with AR-FL (Ahrens-Fath et al. 2005).

Most AR-Vs contain an intact DNA-binding domain (DBD); however, AR8 does not have a functional DBD, and AR-V3 (aka AR6) lacks the second zinc finger of the DBD. As a result of missing DBD, AR8 cannot function as a transcription factor (Yang et al. 2011). Instead, it primarily locates on the plasma membrane and promotes EGF-induced Src activation and AR-FL phosphorylation and transactivation (Yang et al. 2011). In contrast, AR-V3, which still contains the AR DNA-binding interface residing in the first zinc finger of DBD, can constitutively activate AR-responsive promoters in prostate cancer cells (Dehm et al. 2008). Another variant, AR23, has in-frame insertions between the two zinc fingers by retaining part of the intronic sequence. AR23 was shown to exhibit exclusively cytoplasmic activities, promoting the transcriptional activity of nuclear factor- $\kappa \mathrm{B}$ while decreasing the activity of activator protein-1 (Jagla et al. 2007). It is likely that the insertion of the intronic sequence has scrambled the DBD.

Following the DBD is the hinge region, encoded by part of exon 3 and exon 4, which has been shown to harbor the canonical nuclear localization signal. The nuclear localization property is important for the variants to perform their trans-activating function. Although some of the variants do not have the nuclear localization signal, they are still primarily located in the nucleus or have a basal level sufficient for ligand-independent transcriptional activity (Chan et al. 2012). Some mechanisms were proposed for their nuclear localization, such as the existence of a nuclear localization signal-like sequence, lack of nuclear export signal (Saporita et al. 2003, Chan et al. 2012) or tyrosine phosphorylation in the N-terminal domain (Karaca et al. 2015). However, these mechanisms do not appear to satisfactorily cover all the variants with predominant nuclear localization. Characterization of the involved amino acid sequences and understanding the mechanisms that govern their nuclear localization may offer the potential to block AR-V nuclear localization.

\section{AR-V production}

AR-Vs may arise from multiple mechanisms. Genomic rearrangement of the AR gene has been associated with AR-V generation ( $\mathrm{Li}$ et al. 2011, 2012b, Nyquist et al. 2013). Modeling gene rearrangement in prostate cancer cells showed expression of $\mathrm{AR}^{\mathrm{v} 567 \mathrm{es}}$ without AR-FL in clonally selected cells (Nyquist et al. 2013). Although AR gene rearrangement could contribute to AR-V production in the subset of prostate cancers with AR-Vs being the predominant form of AR expressed, other mechanisms, such as the involvement of specific splicing factors, may underlie the co-expression of AR-FL and AR-Vs observed in many prostate cancer specimens (Miyamoto et al. 2015). Nadiminty and coworkers showed that the splicing factor hnRNPA1 is upregulated and correlated with AR-V7 expression level in 22Rv1 cells with acquired enzalutamide resistance (Nadiminty et al. 2015). The recruitment of hnRNPA1 to the AR-V7 and AR-V3 (aka AR-1/2/2b) splicing sites in AR pre-mRNA is increased, but no significant change is observed in the recruitment of hnRNPA1 to the AR-FL splicing sites, suggesting hnRNPA1 can selectively regulate the generation of AR-Vs (Nadiminty et al. 2015). In addition, Liu and coworkers reported that splicing factors U2AF65 and ASF/SF2 can recognize the binding sites near $\mathrm{AR}$ exon $3 \mathrm{~B}$ and facilitate the recruitment of RNA spliceosome to the AR-V7 3' splicing site in $\mathrm{VCaP}$ and LNCaP95 cells after androgen deprivation (Liu et al. 2014b). Unlike the hnRNPA1 in the aforementioned study, the expression of U2AF65 and ASF/SF2 is not changed after androgen deprivation. Instead, increased AR-V7 production is due to elevated AR pre-mRNA substrates for those splicing factors (Liu et al. 2014b). Furthermore, the study by Ferraldeschi and coworkers implicated a role for the molecular chaperone, HSP90, in AR-V7 splicing (Ferraldeschi et al. 2016). HSP90 inhibition leads to the disruption of AR-V7 splicing and reduction of AR-V7 level (Ferraldeschi et al. 2016). Finally, another study highlighted the interplay between the noncoding RNA PCGEM1 and splicing factors in contributing to AR splicing (Zhang et al. 2016). Androgen deprivation was found to induce PCGEM1 redistribution into nuclear speckles, and the interaction between PCGEM1 and U2AF65 promotes AR-V7 splicing (Zhang et al. 2016). Thus, mechanisms governing AR-V production could be cell-context specific and may involve more layers of regulation beyond splicing factors.

\section{Clinical relevance}

Accumulating clinical studies showed an association among AR-V expression and prostate cancer progression, therapy resistance, and poor clinical outcome. AR-Vs can be detected in benign prostate tissues, hormonenaïve prostate cancers and CRPC samples, with the most frequent and highest expression detected in CRPC samples (Guo et al. 2009, Hu et al. 2009, Sun et al. 2010,

Published by Bioscientifica Ltd 
Hornberg et al. 2011, Zhang et al. 2011, Antonarakis et al. 2014, Abeshouse et al. 2015, Qu et al. 2015, Miyamoto et al. 2015, Robinson et al. 2015, Welti et al. 2016). Higher expression of AR-V7 in hormone-naïve prostate tumors has been shown to correlate with increased risk of biochemical recurrence after radical prostatectomy (Guo et al. 2009, Hu et al. 2009) and more rapid progression to CRPC (Qu et al. 2015). Moreover, high levels of AR-V7 mRNA or nuclear AR-V7 protein or detectable expression of $\mathrm{AR}^{\mathrm{v} 567 \mathrm{es}} \mathrm{mRNA}$ in CRPCs are associated with a shorter survival of the patients (Hornberg et al. 2011, Qu et al. 2015, Welti et al. 2016). Thus, AR-V expression appears to be associated with a more lethal form of the disease. In support of this clinical evidence, preclinical studies showed that expression of AR-V7 or ARv567es in prostate cancer cell lines or in prostate epithelium of transgenic mice can induce epithelial-to-mesenchymal transition markers (Cottard et al. 2013, Liu et al. 2013, Sun et al. 2014) and castration-resistant growth of prostate cancer cells (Guo et al. 2009, Sun et al. 2010, Watson et al. 2010).

AR-Vs have also been shown to confer both primary and acquired resistance to abiraterone and enzalutamide in preclinical models (Mostaghel et al. 2011, Li et al. 2013, Nadiminty et al. 2013, Cao et al. 2014, Yamamoto et al. 2015). Significantly, AR-V7 has been indicated to have prognostic value in CRPC patients treated with abiraterone or enzalutamide. In a prospective phase 2 study, Efstathiou and coworkers assessed the AR-V7 protein levels in bone marrow biopsies from 60 patients with bone metastatic CRPC before and after enzalutamide treatment (Efstathiou et al. 2015). The presence of AR-V7 is associated with primary resistance to enzalutamide (Efstathiou et al. 2015). In another study, Antonarakis and coworkers evaluated the AR-V7 mRNA level in circulating tumor cells from metastatic CRPC patients before the initiation of enzalutamide or abiraterone treatment (Antonarakis et al. 2014). None of the patients with AR-V7-positive circulating tumor cells showed a response of prostate-specific antigen (PSA) to enzalutamide or abiraterone, and AR-V7 positivity is associated with a shorter progression-free survival of the patients (Antonarakis et al. 2014). Together, these studies suggested the potential of using AR-Vs as a predictive marker of response to enzalutamide and abiraterone.

The role of AR-Vs in therapy resistance may not be limited to androgen-directed therapies. Preclinical studies indicated that AR-Vs might also contribute to taxane resistance. Paclitaxel, docetaxel and cabazitaxel are members of the taxane family of chemotherapeutic agents. They bind to and stabilize microtubules to suppress microtubule dynamics (Martin \& Kyprianou 2015, Mellado et al. 2016). Recent literature suggested that androgen-induced AR-FL nuclear import, which is facilitated by microtubule, can be inhibited by paclitaxel and docetaxel (Zhu et al. 2010, Darshan et al. 2011, van Soest et al. 2013, Zhang et al. 2015) but may or may not by cabazitaxel (van Soest et al. 2013, de Leeuw et al. 2015, Zhang et al. 2015, Martin et al. 2016). In contrast to AR-FL, AR-V7 is not only resistant to docetaxel and paclitaxel inhibition of nuclear translocation (Thadani-Mulero et al. 2014, Martin et al. 2015, Zhang et al. 2015) but also attenuates the ability of docetaxel and paclitaxel to retain AR-FL in the cytoplasm (Zhang et al. 2015). The role of AR-V7 in contributing to taxane resistance is further supported by the ability of the AR N-terminal domain antagonist EPI-001/002 to enhance the response of AR-V7-expressing CRPC cells to docetaxel treatment in vitro and in vivo (Martin et al. 2015). However, such role of AR-V7 does not appear to be supported by clinical evidence. Two groups examined AR-V7 mRNA levels in circulating tumor cells from CRPC patients before the initiation of taxane chemotherapy. Both showed that the response to taxanes seems to be independent of the AR-V7 status of circulating tumor cells (Antonarakis et al. 2015, Onstenk et al. 2015). In these studies, the methodologies for isolating circulating tumor cells heavily depend on the expression of an epithelial cell marker on circulating tumor cells (Antonarakis et al. 2015, Onstenk et al. 2015). Whether the exclusion of circulating tumor cells that have undergone epithelialto-mesenchymal transition in these studies contributes to the conflicting clinical and preclinical findings is yet to be determined.

\section{Homodimerization and heterodimerization of AR-Vs}

Homodimerization is an essential step for AR-FL to activate target gene expression. The consecutive steps leading to AR-FL homodimerization has been well elucidated (van Royen et al. 2012). Upon ligand binding in the cytoplasm, AR-FL forms intramolecular N-terminal and C-terminal (N/C) interactions, which facilitate nuclear translocation of AR-FL (van Royen et al. 2012). In the nucleus, the intramolecular interactions are followed by a D-box-dimerization-dependent transition to intermolecular N/C interaction (van Royen et al. 2012). Both the intra- and inter-molecular N/C interactions and D-box/D-box interactions are required for AR-FL dimerization (van Royen et al. 2012). Mutations in the

Published by Bioscientifica Ltd. 
N-terminal domain or the D-box can both cause the loss of AR-FL transcriptional ability (van Royen et al. 2012). The knowledge on AR-FL transactivation paved the path for the understanding of AR-V transactivation and identification of critical trans-activating steps for therapeutic targeting. We recently showed that, like liganded AR-FL, dimerization is also required for AR-Vs to transactivate target genes. AR-V7 and $\mathrm{AR}^{\text {v567es }}$ can not only homodimerize but also heterodimerize with each other, and the dimerization is mediated by D-box-D-box interactions (Xu et al. 2015). We further showed that the D-box mutants of AR-V7 and AR567es lose the ability to transactivate target genes and to induce castration-resistant cell growth (Xu et al. 2015). These findings highlight the potential of targeting AR D-box to inhibit the activity of both AR-FL and AR-Vs for CRPC treatment.

\section{Interplays between AR-Vs and AR-FL}

The function of AR-Vs to regulate gene expression has mainly been investigated independent of AR-FL. However, as AR-Vs are often co-expressed with AR-FL in clinical specimens (Miyamoto et al. 2015), the interplays between AR-Vs and AR-FL may be an important mechanism of their actions. Coimmunoprecipitation of $\mathrm{AR}^{\mathrm{v} 567 \mathrm{es}}$ and AR-FL (Sun et al. 2010) as well as co-occupancy of AR-V7 and AR-FL on the PSA promoter (Cao et al. 2014) indicate that there may be direct interactions between AR-FL and AR-Vs. Using two different assays to detect protein dimerization, we recently showed that both AR-V7 and $\mathrm{AR}^{\mathrm{v} 567 \mathrm{es}}$ can heterodimerize with AR-FL (Xu et al. 2015). The heterodimerization induces androgen-independent AR-FL nuclear localization and transcriptional activity (Cao et al. 2014). Interestingly, we found that the promoter of the canonical AR target PSA is co-occupied by AR-V7 and AR-FL, whereas the promoter of the UBE2C gene is bound by AR-V7 only (Cao et al. 2014), suggesting that the AR-V/AR-FL dimers and the AR-V/AR-V dimers may regulate different sets of target genes. This is supported by transcriptome and metabolome data showing that AR-Vs can regulate some canonical AR targets as well as a distinct set of genes/pathways (Guo et al. 2009, Hu et al. 2012, Li et al. 2013, Lu et al. 2014, Chan et al. 2015, Shafi et al. 2015). Identifying the respective binding sites for AR-V/AR-FL dimers and AR-V/AR-V dimers across the genome and elucidating whether the genes and pathways regulated by the AR-V/AR-FL dimers fully overlap with those regulated by AR-FL homodimer could be vital in understanding how AR-Vs contribute to castration resistance.

\section{AR-V cofactors}

It has long been appreciated that AR cofactors play critical roles in modulating AR activity. However, cofactors for AR-Vs have been scarcely addressed. Although the vast majority of AR-Vs have a truncated C-terminal domain, cofactors that interact with the N-terminal domain of AR-FL may still be involved in modulating the activity of AR-Vs. Several groups have profiled the AR-V transcriptome (Guo et al. 2009, Hu et al. 2012, Li et al. 2013, Lu et al. 2014, Chan et al. 2015), however, AR-V gene expression profiles lack consistency in different prostate cancer models (reviewed in Lu et al. 2015). It is possible that AR-Vs can recruit distinct cofactors that may confer target specificity in different cellular context. As AR-Vs can evade androgen-directed therapies, investigation on the cofactors shared by AR-FL and AR-Vs may provide more potent therapeutic targets.

Theoretically, cofactors bound to the N-terminal domain of AR-FL should interact with AR-Vs as well. Gli2, which binds to the Tau5/AF5 region in the $\mathrm{N}$-terminal domain of AR to enhance AR-FL activity (Chen et al. 2010), can also coactivate AR-V7 and ARv567es (Li et al. 2014b). However, there are also cofactors that interact with AR-FL and AR-Vs through different interfaces and with differing affinity. For example, the transcriptional coactivator FHL2 can increase AR-FL transcriptional activity in an agonist- and AF-2-dependent manner (Muller et al. 2000). As most AR-Vs do not contain the AF-2 domain, it is expected that FHL2 would not influence AR-V activity. However, a recent study showed that FHL2 can also act as an AR-V7 coactivator (McGrath et al. 2013). The authors showed that FHL2 accumulates aberrantly in the nucleus in CRPC cells and that nuclear-accumulated FHL2 directly binds to AR-V7 and enhances its transcriptional activity (McGrath et al. 2013). Although the interacting domain on AR-V7 has not been mapped out, it is clear that FHL2 interacts with AR-FL and AR-V7 through binding to different domains. This case also indicates that AR reactivation in CRPC can be contributed by not only altered expression of cofactors but also deregulated subcellular localization of cofactors. Another example is the cofactor MED1. In the presence of androgen, MED1 has been shown to interact with the LBD of AR-FL and enhance androgen-dependent AR-FL activity

Published by Bioscientifica Ltd 
(Wang et al. 2002). In androgen-deprived condition, PI3K/AKT phosphorylated MED1 (p-MED1) can enhance both AR-FL- and ARv567es-mediated UBE2C transcription through an enhancer-promoter chromatin-looping mechanism (Wang et al. 2009, Chen et al. 2011, Liu et al. 2015b). However, ARv567es, with the assistance of the pioneer factor FOXA1, has been shown to be more potent than AR-FL to recruit p-MED1 to the promoter and enhancer regions of UBE2C (Liu et al. 2015b). This may underlie the preferential regulation of UBE2C by AR-Vs over AR-FL in cells co-expressing AR-FL and AR-Vs (Hu et al. 2012, Cao et al. 2014). Together, these findings suggest that MED1 could not only regulate AR-FL activity through different mechanisms when androgen is present vs absent but also contribute to a switch from AR-FL signaling to AR-V signaling.

AR-FL and AR-Vs may compete for binding to certain cofactors in different biological conditions, leading to the activation of different sets of genes. The RhoGTPase guanine nucleotide exchange factor, Vav3, found to be an AR-FL coactivator (Rao et al. 2012), was shown to also enhance AR-V7 and ARv67es transactivation and increase AR-V7 nuclear localization by directly binding to AR-V7 (Peacock et al. 2012). Immunoprecipitation assay showed that AR-V7 may compete with AR-FL for interacting with Vav3 (Peacock et al. 2012).

Some cofactors may regulate not only the activity but also the abundance of AR-FL and AR-Vs. The pioneer factor GATA-binding protein 2 (GATA2) is reported to facilitate AR-FL genomic binding by colocalizing with FOXA1 at the enhancer regions of target genes to produce an accessible chromatin environment for AR-FL before androgen stimulation and by recruiting MED1 to sustain basal enhancer-promoter chromatin looping in the absence of androgen (Wang et al. 2007, He et al. 2014, Wu et al. 2014). It has also been shown to interact with AR-V7 and colocalize with AR-Vs on chromatin (He et al. 2014). At the same time, GATA2 induces the transcription of the AR gene and thereby the levels of both AR-FL and AR-Vs through binding to an extended promoter region of the AR gene (Wang et al. 2007, Bohm et al. 2009, He et al. 2014, Wu et al. 2014). Interestingly, androgen-bound AR represses GATA2 expression (He et al. 2014). Under androgen-deprived condition, with the disruption of this negative-feedback regulatory loop, GATA2 contributes to both overexpression and increased activity of AR-FL and AR-Vs (He et al. 2014). As a result, inhibiting GATA2 has dual efficacy to inactivate AR signaling by ablating both the expression and transcriptional activities of AR-FL and AR-Vs
(He et al. 2014). Preclinical data showed that the small molecule inhibitor of GATA2, K7174, significantly decreased the viability of various GATA2+/AR+ prostate cancer cell lines in vitro and inhibited the growth of LNCaP-abl xenograft tumors (He et al. 2014). All these data suggested a promising role for GATA2 inhibitors in CRPC treatment.

When coexisting in the same cells, corepressors and coactivators may compete for AR-V binding. FOXO1 is a well-known corepressor of AR (Dong et al. 2006, Fan et al. 2007, Liu et al. 2008, Attard et al. 2009). It can inhibit androgen-independent activation of AR-FL (Liu et al. 2008) and the constitutive activity of different AR-Vs (Bohrer et al. 2013, Mediwala et al. 2013). In addition, FOXO1 represses SRC-1-enhanced transcriptional activity of AR-V5 by competing with SRC-1 for binding to the Tau5/AF5 region of AR-V5. Although the Tau5/AF5 region is present in almost all AR-Vs, SRC-1 can only selectively enhance the transcriptional activity of AR-V5 but not the other variants (Bohrer et al. 2013), indicating that the transactivation of different AR-Vs may involve distinct cofactors and mechanisms. It is also possible that different AR-V dimers may recruit specific cofactors to activate gene expression. Further mechanistic study of how these cofactors contribute to CRPC and their interplay with AR-Vs would drive the development of strategies that effectively target the cofactors.

\section{AR-V7 degradation}

In addition to blocking the production and activity of AR-Vs, inducing AR-V protein degradation is another attractive approach to suppress AR-V signaling. $\mathrm{Li}$ and coworkers recently showed that, similar to AR-FL, the AR-V7 protein can be degraded through an Mdm2-mediated ubiquitin-proteasome degradation process and that this process can be accelerated by Akt signaling but is repressed by protein phosphatase- 1 (PP-1) (Li et al. 2015b). Co-targeting the AR and Akt signaling pathways is being tested for CRPC treatment. Would co-suppressing the two pathways lead to a more robust induction of $\mathrm{AR}-\mathrm{Vs}$ and $\mathrm{AR}-\mathrm{V}$-driven tumor progression? If so, would co-targeting the Akt pathway with an agent that can induce AR-V degradation (Li et al. 2012a, Yamashita et al. 2012, Zengerling et al. 2012, Cao et al. 2013, Liu et al. 2014a, Yu et al. 2014, Kwegyir-Afful et al. 2015, Sun et al. 2015) alleviate this problem? These questions need to be carefully addressed.

Published by Bioscientifica Ltd. 


\section{Therapeutic targeting of AR-Vs}

Various approaches have been explored to disrupt AR-V signaling, such as targeting AR N-terminal domain (Myung et al. 2013) or DNA-binding interface (Dalal et al. 2014, Li et al. 2014a), inducing AR-V protein degradation (Li et al. 2012a, Yamashita et al. 2012, Zengerling et al. 2012, Cao et al. 2013, Liu et al. 2014a, Yu et al. 2014, Kwegyir-Afful et al. 2015, Sun et al. 2015), reducing AR-V expression (Mashima et al. 2010, Zhan et al. 2013), inhibiting AR-V chromatin binding (Chan et al. 2015, Li et al. 2015a), disrupting AR-FL and AR-V dimerization (Streicher et al. 2014) or using antisense oligonucleotides against exons shared by AR-FL and AR-Vs (Yamamoto et al. 2015). Here, we describe several AR-V-targeting agents that have entered clinical trials for cancer treatment. EPI-001/002 is a small-molecule, non-steroidal $\mathrm{AR}$ antagonist that covalently binds to AR N-terminal domain to inhibit the transcriptional activities of AR-FL and AR-Vs (Andersen et al. 2010, Sadar 2011, Myung et al. 2013, Kato et al. 2016). It has also been found to act as a selective PPAR $\gamma$ modulator to inhibit AR expression (Brand et al. 2015). EPI-001/002 showed excellent anti-tumor efficacy in various preclinical models of CRPC, and its successor, EPI-506, is being investigated in a phase I/II study in metastatic CRPC patients (Andersen et al. 2010, Sadar 2011, Myung et al. 2013, Brand et al. 2015, Martin and Kyprianou 2015).

Galeterone is another small molecule that can inhibit AR- $V$ activity. It was shown to target AR signaling at three levels, blocking androgen synthesis by inhibiting CYP17, inducing proteasomal degradation of AR-FL and AR-V7 and preventing the binding of androgen to the AR (Handratta et al. 2005, Purushottamachar et al. 2013, Yu et al. 2014, Kwegyir-Afful et al. 2015, Njar \& Brodie 2015). A Phase III trial comparing galeterone to enzalutamide in treatment-naïve metastatic CRPC patients with AR-V7-positive prostate tumors was launched in 2015. Unfortunately, the trial was terminated in July 2016 due to the unlikelihood of galeterone to show improved radiographic progression-free survival in these patients than enzalutamide. Further clinical testing is being planned in metastatic CRPC patients who rapidly progress on enzalutamide or abiraterone or have developed acquired resistance to enzalutamide.

Niclosamide is an FDA-approved anti-helminthic drug that was found to inhibit AR-V7 expression and activity (Liu et al. 2014a). It also targets the IL6-Stat3-AR axis (Liu et al. 2015a). Niclosamide inhibits prostate cancer cell growth and overcomes enzalutamide and abiraterone resistance in preclinical models (Liu et al. 2014a, 2015a, 2016). These promising preclinical data led to the Phase I trial of niclosamide in combination with enzalutamide in AR-V-positive metastatic CRPC patients.

Several second-generation HSP90 inhibitors are in active clinical trials for cancer treatment. HSP90 interacts with the LBD of AR-FL as a molecular chaperone, which is critical for proper folding, hormone binding and transcriptional activity of AR-FL (Vanaja et al. 2002, Ai et al. 2009). It does not affect the activities of AR-Vs (Vanaja et al. 2002, Shafi et al. 2013). However, it has been reported to play a role in AR-V7 splicing (Ferraldeschi et al. 2016). The second-generation HSP90 Inhibitor onalespib was shown to block AR-V7 mRNA splicing and reduce AR-V7 level, supporting further clinical investigation of HSP90 inhibitors against AR-V7-expressing CRPC (Ferraldeschi et al. 2016).

Several bromodomain and extra-terminal domain family (BET) inhibitors have shown promising efficacies in preclinical studies and are currently under clinical trials in CRPC patients (Asangani et al. 2014). Many AR cofactors contain a bromodomain(s), which recognizes acetylated lysine residues and is essential for chromatin binding and remodeling as well as coactivation. A BET inhibitor, JQ1, was shown to disrupt the recruitment of both AR-FL and AR-Vs to target gene loci and block their transactivation (Asangani et al. 2014, Chan et al. 2015). Although it is likely that not all of these agents can be translated into the clinic, these emerging drugs provided promising and innovative approaches to effectively target AR-Vs for treating CRPC.

\section{Conclusion}

The seminar discovery of AR-Vs has revolutionized the field of prostate cancer. It not only broadened our view of how to tackle the AR signaling axis but also provided a most promising prognostic marker for predicting responses of CRPC to current androgen-directed therapies. Various approaches have been explored to disrupt both AR-FL and AR-V signaling. Several emerging drugs, such as EPI-001/002, galeterone, niclosamide, HSP90 inhibitors and BET inhibitors, have shown excellent efficacies to overcome resistance of CRPC to current therapies in preclinical models and are currently under clinical investigation. These innovative approaches of AR targeting have marked the beginning of a new era in prostate cancer treatment. Further investigations of the mechanisms of how AR-Vs are activated to regulate downstream genes and crosstalk with other signaling pathways will continue

Published by Bioscientifica Ltd. 
to benefit the search for more effective therapeutic approaches and targets. Finally, the prognostic influence of AR-Vs may allow the implementation of a tailored therapeutic strategy in selecting patients who may benefit from specific treatment at specific point of disease progression. This will be a major step forward in precision medicine for advanced prostate cancer.

\section{Declaration of interest}

The authors declare no conflict of interest that could be perceived as prejudicing the impartiality of this review.

\section{Funding}

This work was supported by the following grants: NIH/NCI R01CA188609; DOD W81XWH-15-1-0439, W81XWH-16-1-0317 and W81XWH-14-1-0485 and National Natural Science Foundation of China Projects 81272851 and 81430087.

\section{References}

Abeshouse A, Ahn J, Akbani R, Ally A, Amin S, Andry Christopher D, Annala M, Aprikian A, Armenia J, Arora A, et al. 2015 The molecular taxonomy of primary prostate cancer. Cell 163 1011-1025. (doi:10.1016/j.cell.2015.10.025)

Ahrens-Fath I, Politz O, Geserick C \& Haendler B 2005 Androgen receptor function is modulated by the tissue-specific AR45 variant. FEBS Journal 272 74-84. (doi:10.1111/j.1432-1033. 2004.04395.x)

Ai J, Wang Y, Dar JA, Liu J, Liu L, Nelson JB \& Wang Z 2009 HDAC6 regulates androgen receptor hypersensitivity and nuclear localization via modulating Hsp90 acetylation in castrationresistant prostate cancer. Molecular Endocrinology 23 1963-1972. (doi:10.1210/me.2009-0188)

Andersen RJ, Mawji NR, Wang J, Wang G, Haile S, Myung JK, Watt K, Tam T, Yang YC, Banuelos CA, et al. 2010 Regression of castraterecurrent prostate cancer by a small-molecule inhibitor of the amino-terminus domain of the androgen receptor. Cancer Cell $\mathbf{1 7}$ 535-546. (doi:10.1016/j.ccr.2010.04.027)

Antonarakis ES, Lu C, Luber B, Wang H, Chen Y, Nakazawa M, Nadal R, Paller CJ, Denmeade SR, Carducci MA, et al. 2015 Androgen receptor splice variant 7 and efficacy of taxane chemotherapy in patients with metastatic castration-resistant prostate cancer. JAMA Oncology 1 582-591. (doi:10.1001/jamaoncol.2015.1341)

Antonarakis ES, Lu C, Wang H, Luber B, Nakazawa M, Roeser JC, Chen Y, Mohammad TA, Chen Y, Fedor HL, et al. 2014 AR-V7 and resistance to enzalutamide and abiraterone in prostate cancer. New England Journal of Medicine 371 1028-1038. (doi:10.1056/ NEJMoa1315815)

Asangani IA, Dommeti VL, Wang X, Malik R, Cieslik M, Yang R, Escara-Wilke J, Wilder-Romans K, Dhanireddy S, Engelke C, et al. 2014 Therapeutic targeting of BET bromodomain proteins in castration-resistant prostate cancer. Nature 510 278-282. (doi:10.1038/nature13229)

Attard G, Reid AH, Yap TA, Raynaud F, Dowsett M, Settatree S, Barrett M, Parker C, Martins V, Folkerd E, et al. 2008 Phase I clinical trial of a selective inhibitor of CYP17, abiraterone acetate, confirms that castration-resistant prostate cancer commonly remains hormone driven. Journal of Clinical Oncology 26 4563-4571. (doi:10.1200/ JCO.2007.15.9749)
Attard G, Swennenhuis JF, Olmos D, Reid AH, Vickers E, A'Hern R, Levink R, Coumans F, Moreira J, Riisnaes R, et al. 2009 Characterization of ERG, AR and PTEN gene status in circulating tumor cells from patients with castration-resistant prostate cancer. Cancer Research 69 2912-2918. (doi:10.1158/0008-5472. CAN-08-3667)

Bohm M, Locke WJ, Sutherland RL, Kench JG \& Henshall SM 2009 A role for GATA-2 in transition to an aggressive phenotype in prostate cancer through modulation of key androgen-regulated genes. Oncogene 28 3847-3856. (doi:10.1038/onc.2009.243)

Bohrer LR, Liu P, Zhong J, Pan Y, Angstman J, Brand LJ, Dehm SM \& Huang H 2013 FOXO1 binds to the TAU5 motif and inhibits constitutively active androgen receptor splice variants. Prostate $\mathbf{7 3}$ 1017-1027. (doi:10.1002/pros.22649)

Brand LJ, Olson ME, Ravindranathan P, Guo H, Kempema AM, Andrews TE, Chen X, Raj GV, Harki DA \& Dehm SM 2015 EPI-001 is a selective peroxisome proliferator-activated receptor-gamma modulator with inhibitory effects on androgen receptor expression and activity in prostate cancer. Oncotarget 6 3811-3824. (doi:10.18632/oncotarget.2924)

Cao B, Liu X, Li J, Liu S, Qi Y, Xiong Z, Zhang A, Wiese T, Fu X, Gu J, et al. 2013 20(S)-protopanaxadiol-aglycone downregulation of the full-length and splice variants of androgen receptor. International Journal of Cancer 132 1277-1287. (doi:10.1002/ijc.27754)

Cao B, Qi Y, Zhang G, Xu D, Zhan Y, Alvarez X, Guo Z, Fu X, Plymate SR, Sartor O, et al. 2014 Androgen receptor splice variants activating the full-length receptor in mediating resistance to androgen-directed therapy. Oncotarget 5 1646-1656. (doi:10.18632/ oncotarget.1802)

Chan SC \& Dehm SM 2014 Constitutive activity of the androgen receptor. Advances in Pharmacology 70 327-366. (doi:10.1016/b978-012-417197-8.00011-0)

Chan SC, Li Y \& Dehm SM 2012 Androgen receptor splice variants activate androgen receptor target genes and support aberrant prostate cancer cell growth independent of canonical androgen receptor nuclear localization signal. Journal of Biological Chemistry 287 19736-19749. (doi:10.1074/jbc.M112.352930)

Chan SC, Selth LA, Li Y, Nyquist MD, Miao L, Bradner JE, Raj GV, Tilley WD \& Dehm SM 2015 Targeting chromatin binding regulation of constitutively active AR variants to overcome prostate cancer resistance to endocrine-based therapies. Nucleic Acids Research 43 5880-5897. (doi:10.1093/nar/gkv262)

Chen M, Feuerstein MA, Levina E, Baghel PS, Carkner RD, Tanner MJ, Shtutman M, Vacherot F, Terry S, de la Taille A, et al. 2010 Hedgehog/Gli supports androgen signaling in androgen deprived and androgen independent prostate cancer cells. Molecular Cancer 9 89. (doi:10.1186/1476-4598-9-89)

Chen Z, Zhang C, Wu D, Chen H, Rorick A, Zhang X \& Wang Q 2011 Phospho-MED1-enhanced UBE2C locus looping drives castrationresistant prostate cancer growth. EMBO Journal 30 2405-2419. (doi:10.1038/emboj.2011.154)

Cottard F, Asmane I, Erdmann E, Bergerat JP, Kurtz JE \& Ceraline J 2013 Constitutively active androgen receptor variants upregulate expression of mesenchymal markers in prostate cancer cells. PLoS ONE 8 e63466. (doi:10.1371/journal.pone.0063466)

Dalal K, Roshan-Moniri M, Sharma A, Li H, Ban F, Hassona MD, Hsing M, Singh K, LeBlanc E, Dehm S, et al. 2014 Selectively targeting the DNA-binding domain of the androgen receptor as a prospective therapy for prostate cancer. Journal of Biological Chemistry 289 26417-26429. (doi:10.1074/jbc.M114.553818)

Darshan MS, Loftus MS, Thadani-Mulero M, Levy BP, Escuin D, Zhou XK, Gjyrezi A, Chanel-Vos C, Shen R, Tagawa ST, et al. 2011 Taxane-induced blockade to nuclear accumulation of the androgen receptor predicts clinical responses in metastatic prostate cancer. Cancer Research 71 6019-6029. (doi:10.1158/00085472.CAN-11-1417) 
de Bono JS, Logothetis CJ, Molina A, Fizazi K, North S, Chu L, Chi KN, Jones RJ, Goodman OB, Saad F, et al. 2011 Abiraterone and increased survival in metastatic prostate cancer. New England Journal of Medicine 364 1995-2005. (doi:10.1056/NEJMoa1014618)

de Leeuw R, Berman-Booty LD, Schiewer MJ, Ciment SJ, Den RB, Dicker AP, Kelly WK, Trabulsi EJ, Lallas CD, Gomella LG, et al. 2015 Novel actions of next-generation taxanes benefit advanced stages of prostate cancer. Clinical Cancer Research 21 795-807. (doi:10.1158/1078-0432.CCR-14-1358)

Dehm SM, Schmidt LJ, Heemers HV, Vessella RL \& Tindall DJ 2008 Splicing of a novel androgen receptor exon generates a constitutively active androgen receptor that mediates prostate cancer therapy resistance. Cancer Research 68 5469-5477. (doi:10.1158/0008-5472. CAN-08-0594)

Dong XY, Chen C, Sun X, Guo P, Vessella RL, Wang RX, Chung LW, Zhou W \& Dong JT 2006 FOXO1A is a candidate for the 13q14 tumor suppressor gene inhibiting androgen receptor signaling in prostate cancer. Cancer Research 66 6998-7006. (doi:10.1158/00085472.CAN-06-0411)

Efstathiou E, Titus M, Tsavachidou D, Tzelepi V, Wen S, Hoang A, Molina A, Chieffo N, Smith LA, Karlou M, et al. 2012 Effects of abiraterone acetate on androgen signaling in castrate-resistant prostate cancer in bone. Journal of Clinical Oncology 30 637-643. (doi:10.1200/JCO.2010.33.7675)

Efstathiou E, Titus M, Wen S, Hoang A, Karlou M, Ashe R, Tu SM, Aparicio A, Troncoso P, Mohler J, et al. 2015 Molecular characterization of enzalutamide-treated bone metastatic castrationresistant prostate cancer. European Urology 67 53-60. (doi:10.1016/ j.eururo.2014.05.005)

Egan A, Dong Y, Zhang H, Qi Y, Balk SP \& Sartor O 2014 Castrationresistant prostate cancer: adaptive responses in the androgen axis. Cancer Treatment Reviews 40 426-433. (doi:10.1016/j.ctrv. 2013.09.011)

Fan W, Yanase T, Morinaga H, Okabe T, Nomura M, Daitoku H, Fukamizu A, Kato S, Takayanagi R \& Nawata H 2007 Insulin-like growth factor 1 /insulin signaling activates androgen signaling through direct interactions of Foxo1 with androgen receptor. Journal of Biological Chemistry 282 7329-7338. (doi:10.1074/jbc. M610447200)

Ferraldeschi R, Welti J, Powers MV, Yuan W, Smyth T, Seed G, Riisnaes R, Hedayat S, Wang H, Crespo M, et al. 2016 Second-generation HSP90 inhibitor onalespib blocks mRNA splicing of androgen receptor variant 7 in prostate cancer cells. Cancer Research 76 2731-2742. (doi:10.1158/0008-5472.CAN-15-2186)

Fizazi K, Scher HI, Molina A, Logothetis CJ, Chi KN, Jones RJ, Staffurth JN, North S, Vogelzang NJ, Saad F, et al. 2012 Abiraterone acetate for treatment of metastatic castration-resistant prostate cancer: final overall survival analysis of the COU-AA-301 randomised, double-blind, placebo-controlled phase 3 study. Lancet Oncology 13 983-992. (doi:10.1016/S1470-2045(12)70379-0)

Gelmann EP 2002 Molecular biology of the androgen receptor. Journal of Clinical Oncology 20 3001-3015. (doi:10.1200/JCO.2002.10.018)

Guo Z, Yang X, Sun F, Jiang R, Linn DE, Chen H, Chen H, Kong X, Melamed J, Tepper CG, et al. 2009 A novel androgen receptor splice variant is up-regulated during prostate cancer progression and promotes androgen depletion-resistant growth. Cancer Research 69 2305-2313. (doi:10.1158/0008-5472.CAN-08-3795)

Handratta VD, Vasaitis TS, Njar VC, Gediya LK, Kataria R, Chopra P, Newman D Jr, Farquhar R, Guo Z, Qiu Y, et al. 2005 Novel C-17-heteroaryl steroidal CYP17 inhibitors/antiandrogens: synthesis, in vitro biological activity, pharmacokinetics, and antitumor activity in the LAPC4 human prostate cancer xenograft model. Journal of Medicinal Chemistry 48 2972-2984. (doi:10.1021/ jm040202w)

He B, Lanz RB, Fiskus W, Geng C, Yi P, Hartig SM, Rajapakshe K, Shou J, Wei L, Shah SS, et al. 2014 GATA2 facilitates steroid receptor coactivator recruitment to the androgen receptor complex. PNAS 111 18261-18266. (doi:10.1073/pnas.1421415111)

Hornberg E, Ylitalo EB, Crnalic S, Antti H, Stattin P, Widmark A, Bergh A \& Wikstrom P 2011 Expression of androgen receptor splice variants in prostate cancer bone metastases is associated with castration-resistance and short survival. PLOS ONE 6 e19059. (doi:10.1371/journal.pone.0019059)

Hu R, Dunn TA, Wei S, Isharwal S, Veltri RW, Humphreys E, Han M, Partin AW, Vessella RL, Isaacs WB, et al. 2009 Ligand-independent androgen receptor variants derived from splicing of cryptic exons signify hormone-refractory prostate cancer. Cancer Research 69 16-22. (doi:10.1158/0008-5472.CAN-08-2764)

Hu R, Isaacs WB \& Luo J 2011 A snapshot of the expression signature of androgen receptor splicing variants and their distinctive transcriptional activities. Prostate 71 1656-1667. (doi:10.1002/ pros.21382)

Hu R, Lu C, Mostaghel EA, Yegnasubramanian S, Gurel M, Tannahill C, Edwards J, Isaacs WB, Nelson PS, Bluemn E, et al. 2012 Distinct transcriptional programs mediated by the ligand-dependent fulllength androgen receptor and its splice variants in castrationresistant prostate cancer. Cancer Research 72 3457-3462. (doi:10.1158/0008-5472.CAN-11-3892)

Jagla M, Feve M, Kessler P, Lapouge G, Erdmann E, Serra S, Bergerat JP \& Ceraline J 2007 A splicing variant of the androgen receptor detected in a metastatic prostate cancer exhibits exclusively cytoplasmic actions. Endocrinology 148 4334-4343. (doi:10.1210/en.2007-0446)

Kahn B, Collazo J \& Kyprianou N 2014 Androgen receptor as a driver of therapeutic resistance in advanced prostate cancer. International Research Journal of Biological Sciences 10 588-595. (doi:10.7150/ ijbs.8671)

Karaca M, Liu Y, Zhang Z, De Silva D, Parker JS, Earp HS \& Whang YE 2015 Mutation of androgen receptor N-terminal phosphorylation site Tyr-267 leads to inhibition of nuclear translocation and DNA binding. PLOS ONE 10 e0126270. (doi:10.1371/journal. pone.0126270)

Kato M, Banuelos CA, Imamura Y, Leung JK, Caley DP, Wang J, Mawji NR \& Sadar MD 2016 Cotargeting androgen receptor splice variants and mTOR signaling pathway for the treatment of castration-resistant prostate cancer. Clinical Cancer Research 22 2744-2754. (doi:10.1158/1078-0432.CCR-15-2119)

Knudsen KE \& Scher HI 2009 Starving the addiction: new opportunities for durable suppression of AR signaling in prostate cancer. Clinical Cancer Research 15 4792-4798. (doi:10.1158/10780432.CCR-08-2660)

Kwegyir-Afful AK, Ramalingam S, Purushottamachar P, Ramamurthy VP \& Njar VC 2015 Galeterone and VNPT55 induce proteasomal degradation of AR/AR-V7, induce significant apoptosis via cytochrome $\mathrm{c}$ release and suppress growth of castration resistant prostate cancer xenografts in vivo. Oncotarget 6 27440-27460. (doi:10.18632/oncotarget.4578)

Li Y, Alsagabi M, Fan D, Bova GS, Tewfik AH \& Dehm SM 2011 Intragenic rearrangement and altered RNA splicing of the androgen receptor in a cell-based model of prostate cancer progression. Cancer Research 71 2108-2117. (doi:10.1158/0008-5472.CAN-10-1998)

Li H, Ban F, Dalal K, Leblanc E, Frewin K, Ma D, Adomat H, Rennie PS \& Cherkasov A 2014a Discovery of small-molecule inhibitors selectively targeting the DNA-binding domain of the human androgen receptor. Journal of Medicinal Chemistry 57 6458-6467. (doi:10.1021/jm500802j)

Li N, Chen M, Truong S, Yan C \& Buttyan R 2014b Determinants of Gli2 co-activation of wildtype and naturally truncated androgen receptors. Prostate 74 1400-1410. (doi:10.1002/pros.22855)

Li Y, Chan SC, Brand LJ, Hwang TH, Silverstein KA \& Dehm SM 2013 Androgen receptor splice variants mediate enzalutamide resistance in castration-resistant prostate cancer cell lines. Cancer Research $\mathbf{7 3}$ 483-489. (doi:10.1158/0008-5472.CAN-12-3630) 
Li X, Liu Z, Xu X, Blair CA, Sun Z, Xie J, Lilly MB \& Zi X 2012a Kava components down-regulate expression of $\mathrm{AR}$ and $\mathrm{AR}$ splice variants and reduce growth in patient-derived prostate cancer xenografts in mice. PLOS ONE 7 e31213. (doi:10.1371/journal.pone.0031213)

Li Y, Hwang TH, Oseth LA, Hauge A, Vessella RL, Schmechel SC, Hirsch B, Beckman KB, Silverstein KA \& Dehm SM 2012b AR intragenic deletions linked to androgen receptor splice variant expression and activity in models of prostate cancer progression. Oncogene 31 4759-4767. (doi:10.1038/onc.2011.637)

Li H, Xie N, Gleave ME \& Dong X 2015a Catalytic inhibitors of DNA topoisomerase II suppress the androgen receptor signaling and prostate cancer progression. Oncotarget 6 20474-20484. (doi:10.18632/oncotarget.4105)

Li Y, Xie N, Gleave ME, Rennie PS \& Dong X 2015b AR-v7 protein expression is regulated by protein kinase and phosphatase. Oncotarget 6 33743-33754. (doi:10.18632/oncotarget.5608)

Liu C, Armstrong C, Zhu Y, Lou W \& Gao AC 2016 Niclosamide enhances abiraterone treatment via inhibition of androgen receptor variants in castration resistant prostate cancer. Oncotarget 7 32210-32220. (doi:10.18632/oncotarget.8493)

Liu P, Li S, Gan L, Kao TP \& Huang H 2008 A transcription-independent function of FOXO1 in inhibition of androgen-independent activation of the androgen receptor in prostate cancer cells. Cancer Research 68 10290-10299. (doi:10.1158/0008-5472.CAN-08-2038)

Liu C, Lou W, Armstrong C, Zhu Y, Evans CP \& Gao AC $2015 a$ Niclosamide suppresses cell migration and invasion in enzalutamide resistant prostate cancer cells via Stat3-AR axis inhibition. Prostate $\mathbf{7 5}$ 1341-1353. (doi:10.1002/pros.23015)

Liu G, Sprenger C, Wu PJ, Sun S, Uo T, Haugk K, Epilepsia KS \& Plymate S 2015 $b$ MED1 mediates androgen receptor splice variant induced gene expression in the absence of ligand. Oncotarget 6 288-304. (doi:10.18632/oncotarget.2672)

Liu C, Lou W, Zhu Y, Nadiminty N, Schwartz CT, Evans CP \& Gao AC $2014 a$ Niclosamide inhibits androgen receptor variants expression and overcomes enzalutamide resistance in castration-resistant prostate cancer. Clinical Cancer Research 20 3198-3210. (doi:10.1158/1078-0432.CCR-13-3296)

Liu LL, Xie N, Sun S, Plymate S, Mostaghel E \& Dong X 2014b Mechanisms of the androgen receptor splicing in prostate cancer cells. Oncogene 33 3140-3150. (doi:10.1038/onc.2013.284)

Liu G, Sprenger C, Sun S, Epilepsia KS, Haugk K, Zhang X, Coleman I, Nelson PS \& Plymate S 2013 AR variant ARv567es induces carcinogenesis in a novel transgenic mouse model of prostate cancer. Neoplasia 15 1009-1017. (doi:10.1593/neo.13784)

Lu J, Lonergan PE, Nacusi LP, Wang L, Schmidt LJ, Sun Z, van der Steen T, Boorjian SA, Kosari F, Vasmatzis G, et al. 2014 The cistrome and gene signature of androgen receptor splice variants in castration-resistant prostate cancer cells. Journal of Urology 193 690-698. (doi:10.1016/j.juro.2014.08.043)

Lu J, Van der Steen T \& Tindall DJ 2015 Are androgen receptor variants a substitute for the full-length receptor? Nature Reviews Urology 12 137-144. (doi:10.1038/nrurol.2015.13)

Martin SK, Banuelos CA, Sadar MD \& Kyprianou N 2015 N-terminal targeting of androgen receptor variant enhances response of castration resistant prostate cancer to taxane chemotherapy. Molecular Oncology 9 628-639. (doi:10.1016/j.molonc.2014.10.014)

Martin SK \& Kyprianou N 2015 Exploitation of the androgen receptor to overcome taxane resistance in advanced prostate cancer. Advances in Cancer Research 127 123-158. (doi:10.1016/bs.acr.2015.03.001)

Martin SK, Pu H, Penticuff JC, Cao Z, Horbinski C \& Kyprianou N 2016 Multinucleation and mesenchymal-to-epithelial transition alleviate resistance to combined cabazitaxel and antiandrogen therapy in advanced prostate cancer. Cancer Research 76 912-926. (doi:10.1158/0008-5472.CAN-15-2078)

Mashima T, Okabe S \& Seimiya H 2010 Pharmacological targeting of constitutively active truncated androgen receptor by nigericin and suppression of hormone-refractory prostate cancer cell growth. Molecular Pharmacology 78 846-854. (doi:10.1124/mol.110.064790)

McGrath MJ, Binge LC, Sriratana A, Wang H, Robinson PA, Pook D, Fedele CG, Brown S, Dyson JM, Cottle DL, et al. 2013 Regulation of the transcriptional coactivator FHL2 licenses activation of the androgen receptor in castrate-resistant prostate cancer. Cancer Research 73 5066-5079. (doi:10.1158/0008-5472.CAN-12-4520)

Mediwala SN, Sun H, Szafran AT, Hartig SM, Sonpavde G, Hayes TG, Thiagarajan P, Mancini MA \& Marcelli M 2013 The activity of the androgen receptor variant AR-V7 is regulated by FOXO1 in a PTEN-PI3K-AKT-dependent way. Prostate 73 267-277. (doi:10.1002/ pros.22566)

Mellado B, Jimenez N, Marin-Aguilera M \& Reig O 2016 Diving into cabazitaxel's mode of action: more than a taxane for the treatment of castration-resistant prostate cancer patients. Clinical Genitourinary Cancer 14 265-270. (doi:10.1016/j.clgc.2015.12.030)

Miyamoto DT, Zheng Y, Wittner BS, Lee RJ, Zhu H, Broderick KT, Desai R, Fox DB, Brannigan BW, Trautwein J, et al. 2015 RNA-Seq of single prostate CTCs implicates noncanonical Wnt signaling in antiandrogen resistance. Science 349 1351-1356. (doi:10.1126/ science.aab0917)

Mostaghel EA, Marck BT, Plymate SR, Vessella RL, Balk S, Matsumoto AM, Nelson PS \& Montgomery RB 2011 Resistance to CYP17A1 inhibition with abiraterone in castration-resistant prostate cancer: induction of steroidogenesis and androgen receptor splice variants. Clinical Cancer Research 17 5913-5925. (doi:10.1158/ 1078-0432.CCR-11-0728)

Muller JM, Isele U, Metzger E, Rempel A, Moser M, Pscherer A, Breyer T, Holubarsch C, Buettner R \& Schule R 2000 FHL2, a novel tissue-specific coactivator of the androgen receptor. EMBO Journal 19 359-369. (doi:10.1093/emboj/19.3.359)

Myung JK, Banuelos CA, Fernandez JG, Mawji NR, Wang J, Tien AH, Yang YC, Tavakoli I, Haile S, Watt K, et al. 2013 An androgen receptor N-terminal domain antagonist for treating prostate cancer. Journal of Clinical Investigation 123 2948-2960. (doi:10.1172/ JCI66398)

Nadiminty N, Tummala R, Liu C, Lou W, Evans CP \& Gao AC 2015 NF-kappaB2/p52:c-Myc:hnRNPA1 pathway regulates expression of androgen receptor splice variants and enzalutamide sensitivity in prostate cancer. Molecular Cancer Therapeutics 14 1884-1895. (doi:10.1158/1535-7163.MCT-14-1057)

Nadiminty N, Tummala R, Liu C, Yang J, Lou W, Evans CP \& Gao AC 2013 NF-kappaB2/p52 induces resistance to enzalutamide in prostate cancer: role of androgen receptor and its variants. Molecular Cancer Therapeutics 12 1629-1637. (doi:10.1158/1535-7163.MCT-13-0027)

Njar VC \& Brodie AM 2015 Discovery and development of Galeterone (TOK-001 or VN/124-1) for the treatment of all stages of prostate cancer. Journal of Medicinal Chemistry 58 2077-2087. (doi:10.1021/ jm501239f)

Nyquist MD, Li Y, Hwang TH, Manlove LS, Vessella RL, Silverstein KA, Voytas DF \& Dehm SM 2013 TALEN-engineered AR gene rearrangements reveal endocrine uncoupling of androgen receptor in prostate cancer. PNAS 110 17492-17497. (doi:10.1073/ pnas.1308587110)

Onstenk W, Sieuwerts AM, Kraan J, Van M, Nieuweboer AJ, Mathijssen RH, Hamberg P, Meulenbeld HJ, De Laere B, Dirix LY, et al. 2015 Efficacy of cabazitaxel in castration-resistant prostate cancer is independent of the presence of AR-V7 in circulating tumor cells. European Urology 68 939-945. (doi:10.1016/j. eururo.2015.07.007)

Peacock SO, Fahrenholtz CD \& Burnstein KL 2012 Vav3 enhances androgen receptor splice variant activity and is critical for castration-resistant prostate cancer growth and survival. Molecular Endocrinology 26 1967-1979. (doi:10.1210/me.2012-1165)

Purushottamachar P, Godbole AM, Gediya LK, Martin MS, Vasaitis TS, Kwegyir-Afful AK, Ramalingam S, Ates-Alagoz Z \& Njar VC 2013 
Systematic structure modifications of multitarget prostate cancer drug candidate galeterone to produce novel androgen receptor down-regulating agents as an approach to treatment of advanced prostate cancer. Journal of Medicinal Chemistry $\mathbf{5 6}$ 4880-4898. (doi:10.1021/jm400048v)

Qu Y, Dai B, Ye D, Kong Y, Chang K, Jia Z, Yang X, Zhang H, Zhu Y \& Shi G 2015 Constitutively active AR-V7 plays an essential role in the development and progression of castration-resistant prostate cancer. Scientific Reports 5 7654. (doi:10.1038/srep07654)

Rao S, Lyons LS, Fahrenholtz CD, Wu F, Farooq A, Balkan W \& Burnstein KL 2012 A novel nuclear role for the Vav3 nucleotide exchange factor in androgen receptor coactivation in prostate cancer. Oncogene 31 716-727. (doi:10.1038/onc.2011.273)

Robinson D, Van Allen EM, Wu YM, Schultz N, Lonigro RJ, Mosquera JM, Montgomery B, Taplin ME, Pritchard CC, Attard G, et al. 2015 Integrative clinical genomics of advanced prostate cancer. Cell 161 1215-1228. (doi:10.1016/j.cell.2015.05.001)

Ryan CJ, Smith MR, de Bono JS, Molina A, Logothetis CJ, de Souza P, Fizazi K, Mainwaring P, Piulats JM, Ng S, et al. 2013 Abiraterone in metastatic prostate cancer without previous chemotherapy. New England Journal of Medicine 368 138-148. (doi:10.1056/ NEJMoa1209096)

Sadar MD 2011 Small molecule inhibitors targeting the 'achilles' heel' of androgen receptor activity. Cancer Research 71 1208-1213. (doi:10.1158/0008-5472.CAN_10-3398)

Saporita AJ, Zhang Q, Navai N, Dincer Z, Hahn J, Cai X \& Wang Z 2003 Identification and characterization of a ligand-regulated nuclear export signal in androgen receptor. Journal of Biological Chemistry 278 41998-42005. (doi:10.1074/jbc.M302460200)

Scher HI, Fizazi K, Saad F, Taplin ME, Sternberg CN, Miller K, de WR, Mulders P, Chi KN, Shore ND, et al. 2012 Increased survival with enzalutamide in prostate cancer after chemotherapy. New England Journal of Medicine 367 1187-1197. (doi:10.1056/ NEJMoa1207506)

Shafi AA, Cox MB \& Weigel NL 2013 Androgen receptor splice variants are resistant to inhibitors of Hsp90 and FKBP52, which alter androgen receptor activity and expression. Steroids 78 548-554. (doi:10.1016/j.steroids.2012.12.013)

Shafi AA, Putluri V, Arnold JM, Tsouko E, Maity S, Roberts JM, Coarfa C, Frigo DE, Putluri N, Sreekumar A, et al. 2015 Differential regulation of metabolic pathways by androgen receptor (AR) and its constitutively active splice variant, AR-V7, in prostate cancer cells. Oncotarget 6 31997-32012. (doi:10.18632/oncotarget.5585)

Streicher W, Luedeke M, Azoitei A, Zengerling F, Herweg A, Genze F, Schrader MG, Schrader AJ \& Cronauer MV 2014 Stilbene induced inhibition of androgen receptor dimerization: implications for AR and ARDeltaLBD-signalling in human prostate cancer cells. PLoS ONE 9 e98566. (doi:10.1371/journal.pone.0098566)

Sun F, Chen HG, Li W, Yang X, Wang X, Jiang R, Guo Z, Chen H, Huang J, Borowsky AD, et al. 2014 Androgen receptor splice variant AR3 promotes prostate cancer via modulating expression of autocrine/paracrine factors. Journal of Biological Chemistry 289 1529-1539. (doi:10.1074/jbc.M113.492140)

Sun F, Indran IR, Zhang ZW, Tan MH, Li Y, Lim ZL, Hua R, Yang C, Soon FF, Li J, et al. 2015 A novel prostate cancer therapeutic strategy using icaritin-activated arylhydrocarbon-receptor to co-target androgen receptor and its splice variants. Carcinogenesis 36 757-768. (doi:10.1093/carcin/bgv040)

Sun S, Sprenger CC, Vessella RL, Haugk K, Soriano K, Mostaghel EA, Page ST, Coleman IM, Nguyen HM, Sun H, et al. 2010 Castration resistance in human prostate cancer is conferred by a frequently occurring androgen receptor splice variant. Journal of Clinical Investigation 120 2715-2730. (doi:10.1172/JCI41824)

Thadani-Mulero M, Portella L, Sun S, Sung M, Matov A, Vessella RL, Corey E, Nanus DM, Plymate SR \& Giannakakou P 2014 Androgen receptor splice variants determine taxane sensitivity in prostate cancer. Cancer Research 74 2270-2282. (doi:10.1158/0008-5472. CAN-13-2876)

Tran C, Ouk S, Clegg NJ, Chen Y, Watson PA, Arora V, Wongvipat J, Smith-Jones PM, Yoo D, Kwon A, et al. 2009 Development of a second-generation antiandrogen for treatment of advanced prostate cancer. Science 324 787-790. (doi:10.1126/science.1168175)

van Royen ME, van Cappellen WA, de VC, Houtsmuller AB \& Trapman J 2012 Stepwise androgen receptor dimerization. Journal of Cell Science 125 1970-1979. (doi:10.1242/jcs.096792)

van Soest RJ, van Royen ME, de Morree ES, Moll JM, Teubel W, Wiemer EA, Mathijssen RH, de Wit R \& van Weerden WM 2013 Cross-resistance between taxanes and new hormonal agents abiraterone and enzalutamide may affect drug sequence choices in metastatic castration-resistant prostate cancer. European Journal of Cancer 49 3821-3830. (doi:10.1016/j.ejca.2013.09.026)

Vanaja DK, Mitchell SH, Toft DO \& Young CY 2002 Effect of geldanamycin on androgen receptor function and stability. Cell Stress and Chaperones 7 55-64. (doi:10.1379/1466-1268(2002) 007<0055:EOGOAR>2.0.CO;2)

Wang Q, Li W, Liu XS, Carroll JS, Janne OA, Keeton EK, Chinnaiyan AM, Pienta KJ \& Brown M 2007 A hierarchical network of transcription factors governs androgen receptor-dependent prostate cancer growth. Molecular Cell 27 380-392. (doi:10.1016/ j.molcel.2007.05.041)

Wang Q, Li W, Zhang Y, Yuan X, Xu K, Yu J, Chen Z, Beroukhim R, Wang H, Lupien $M$, et al. 2009 Androgen receptor regulates a distinct transcription program in androgen-independent prostate cancer. Cell 138 245-256. (doi:10.1016/j.cell.2009.04.056)

Wang Q, Sharma D, Ren Y \& Fondell JD 2002 A coregulatory role for the TRAP-mediator complex in androgen receptor-mediated gene expression. Journal of Biological Chemistry 277 42852-42858. (doi:10.1074/jbc.M206061200)

Watson PA, Chen YF, Balbas MD, Wongvipat J, Socci ND, Viale A, Kim K \& Sawyers CL 2010 Constitutively active androgen receptor splice variants expressed in castration-resistant prostate cancer require fulllength androgen receptor. PNAS 107 16759-16765. (doi:10.1073/ pnas.1012443107)

Welti J, Rodrigues DN, Sharp A, Sun S, Lorente D, Riisnaes R, Figueiredo I, Zafeiriou Z, Rescigno P, de Bono JS, et al. 2016 Analytical validation and clinical qualification of a new immunohistochemical assay for androgen receptor splice variant-7 protein expression in metastatic castration-resistant prostate cancer. European Urology 70 599-608. (doi:10.1016/j.eururo.2016.03.049)

Wu D, Sunkel B, Chen Z, Liu X, Ye Z, Li Q, Grenade C, Ke J, Zhang C, Chen H, et al. 2014 Three-tiered role of the pioneer factor GATA2 in promoting androgen-dependent gene expression in prostate cancer. Nucleic Acids Research 42 3607-3622. (doi:10.1093/nar/gkt1382)

Xu D, Zhan Y, Qi Y, Cao B, Bai S, Xu W, Gambhir SS, Lee P, Sartor O, Flemington EK, et al. 2015 Androgen receptor splice variants dimerize to transactivate target genes. Cancer Research 75 3663-3671. (doi:10.1158/0008-5472.CAN-15-0381)

Yamamoto Y, Loriot Y, Beraldi E, Zhang F, Wyatt AW, Nakouzi NA, Mo F, Zhou T, Kim Y, Monia BP, et al. 2015 Generation 2.5 antisense oligonucleotides targeting the androgen receptor and its splice variants suppress enzalutamide-resistant prostate cancer cell growth. Clinical Cancer Research 21 1675-1687. (doi:10.1158/1078-0432. CCR-14-1108)

Yamashita S, Lai KP, Chuang KL, Xu D, Miyamoto H, Tochigi T, Pang ST, Li L, Arai Y, Kung HJ, et al. 2012 ASC-J9 suppresses castrationresistant prostate cancer growth through degradation of full-length and splice variant androgen receptors. Neoplasia 14 74-83. (doi:10.1593/neo.111436)

Yang X, Guo Z, Sun F, Li W, Alfano A, Shimelis H, Chen M, Brodie AM, Chen H, Xiao Z, et al. 2011 Novel membrane-associated androgen receptor splice variant potentiates proliferative and survival http://erc.endocrinology-journals.org

DOI: 10.1530/ERC-16-0298
(C) 2016 Society for Endocrinology Printed in Great Britain 
responses in prostate cancer cells. Journal of Biological Chemistry $\mathbf{2 8 6}$ 36152-36160. (doi:10.1074/jbc.M111.265124)

Yu Z, Cai C, Gao S, Simon NI, Shen HC \& Balk SP 2014 Galeterone prevents androgen receptor binding to chromatin and enhances degradation of mutant androgen receptor. Clinical Cancer Research 20 4075-4085. (doi:10.1158/1078-0432.CCR-14-0292)

Zengerling F, Streicher W, Schrader AJ, Schrader M, Nitzsche B, Cronauer MV \& Hopfner M 2012 Effects of sorafenib on C-terminally truncated androgen receptor variants in human prostate cancer cells. International Journal of Molecular Sciences $\mathbf{1 3}$ 11530-11542. (doi:10.3390/ijms130911530)

Zhan Y, Cao B, Qi Y, Liu S, Zhang Q, Zhou W, Xu D, Lu H, Sartor O, Kong W, et al. 2013 Methylselenol prodrug enhances MDV3100 efficacy for treatment of castration-resistant prostate cancer. International Journal of Cancer 133 2225-2233. (doi:10.1002/ ijc.28202)
Zhang G, Liu X, Li J, Ledet E, Alvarez X, Qi Y, Fu X, Sartor O, Dong Y \& Zhang H 2015 Androgen receptor splice variants circumvent AR blockade by microtubule-targeting agents. Oncotarget 6 23358-23371. (doi:10.18632/oncotarget.4396)

Zhang X, Morrissey C, Sun S, Ketchandji M, Nelson PS, True LD, Vakar-Lopez F, Vessella RL \& Plymate SR 2011 Androgen receptor variants occur frequently in castration resistant prostate cancer metastases. PLoS ONE 6 e27970. (doi:10.1371/journal.pone.0027970)

Zhang Z, Zhou N, Huang J, Ho TT, Zhu Z, Qiu Z, Zhou X, Bai C, Wu F, $\mathrm{Xu} \mathrm{M}$, et al. 2016 Regulation of androgen receptor splice variant AR3 by PCGEM1. Oncotarget 7 15481-15491. (doi:10.18632/ oncotarget.7139)

Zhu ML, Horbinski CM, Garzotto M, Qian DZ, Beer TM \& Kyprianou N 2010 Tubulin-targeting chemotherapy impairs androgen receptor activity in prostate cancer. Cancer Research 70 7992-8002. (doi:10.1158/0008-5472.CAN-10-0585)

Received in final form 27 September 2016

Accepted 4 October 2016

Accepted Preprint published online 4 October 2016
Published by Bioscientifica Ltd. 